\title{
Una revista de presente que mira al futuro
}

\author{
N. Floro Andrés Rodríguez ${ }^{1}$, Jesús C. Gómez ${ }^{2}$ \\ 1. Director de Farmacéuticos Comunitarios. 2. Presidente de SEFAC.
}

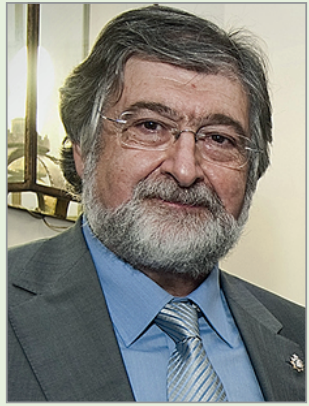

N. Floro Andrés Rodríguez

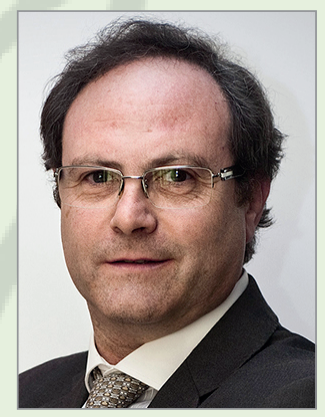

Jesús C. Gómez
FARMACÉUTICOS COMUNITARIOS da un nuevo paso adelante. Desde su nacimiento en 2009 con su cabecera actual y como heredera de e-farmacéutico comunitario, la revista de SEFAC ha experimentado una continua progresión en busca de dos objetivos claros: por un lado, promover, fomentar y consolidar la investigación en farmacia comunitaria en España acercando también a los socios asuntos profesionales relevantes, y, por otro, convertirse en la revista científica de referencia en la publicación de artículos y trabajos de investigación realizados por farmacéuticos comunitarios o de interés para nuestro colectivo.

En estos años la investigación en farmacia comunitaria ha crecido, tomado fuerza e incrementado progresivamente su calidad. Aspectos todos que siguen siendo nuestro objetivo. Todavía muchos buenos trabajos de investigación se quedan en simples comunicaciones en un congreso. Debemos hacer el esfuerzo de construir, a partir del póster, un buen artículo científico para que los resultados obtenidos alcancen la difusión que merecen. SEFAC pone los medios para conseguirlo: la formación necesaria para realizar una investigación, el apoyo por parte del comité editorial, las revisiones de un riguroso comité científico y una revista que pretende tener cada vez una mayor calidad para que a nivel mundial pueda conocerse.

Si ya en enero del año 2013 se presentaba la página web de nuestra revista (www.farmaceuticoscomunitarios.org), con el propósito de mejorar la difusión de sus contenidos, ahora se da otro salto para reforzar los fines apuntados en las líneas anteriores. Y lo hacemos apostando por un cambio de formato que convierte a FARMACÉUTICOS COMUNITARIOS a partir de ahora en una publicación más moderna y completamente electrónica.

Con el presente número, la revista sigue consolidándose y deja atrás el papel para adaptarse así a la realidad de nuestro tiempo y muy especialmente responde a la tendencia mayoritaria en las principales revistas cientificas del sector biosanitario, tanto a nivel nacional como internacional. La publicación en formato electrónico ofrece ventajas encaminadas a continuar con la expansión de la revista en todos sus ámbitos. En particular el formato electrónico da una mayor libertad en cuanto a la limitación formal de contenidos y permite la inclusión de material multimedia, lo que hasta ahora no era posible.
Otro objetivo importante para nuestra revisita es su indexación. Hasta la fecha FARMACÉUTICOS COMUNITARIOS ha conseguido estar indexada en bases de datos como Compludoc, Dialnet, Dulcinea y Latindex y con este cambio perseguimos aumentar nuestra presencia en otras bases de datos. De hecho, la revista ya ha sido aceptada y está en proceso de indexación en CABI-Global Health, CABI-CAB Abstracts, EBSCO, y SIIC Databases (Sociedad Iberoamericana de Información Científica) y se está trabajando para ampliar aún más esta lista en los próximos meses.

Pero, además, esta nueva etapa que ahora iniciamos introduce otras novedades. Pretendemos conseguir una importante difusión en Hispanoamérica: sabemos que las webs de SEFAC y de la revista son frecuentemente visitadas por colegas americanos del ámbito de la farmacia comunitaria y queremos responder a ese interés. Por ello se ha acordado la apertura a artículos y trabajos de autores procedentes de otros países que ejerzan en farmacia comunitaria, independientemente de que sean o no socios de SEFAC. También se abre la revista excepcionalmente a farmacéuticos que ejerzan en otros campos de la Farmacia así como a los contenidos que puedan aportar, siempre y cuando esos contenidos sean considerados útiles e interesantes para la labor asistencial del farmacéutico comunitario, aunque no se hayan desarrollado específicamente en su campo de actuación.

En el presente número, el primero del año 2014 (la periodicidad trimestral se mantiene), el lector podrá encontrar publicada una actualización de las instrucciones para autores, donde se da cuenta de muchos de los cambios comentados en estas líneas.

Aprovechando el cambio a formato electrónico, SEFAC ha decidido dar a todos los lectores acceso a los contenidos completos. Es una forma más de contribuir a que se conozca cómo se merece la actividad investigadora y asistencial que realizan las farmacias comunitarias colaborando en la mejora de la salud de nuestros conciudadanos.

En definitiva, FARMACÉUTICOS COMUNITARIOS sigue creciendo con la convicción que SEFAC posee de la trascendencia que para nuestra profesión tiene disponer de una revista científica propia, en la que todos los que nos preocupamos por nuestro avance como profesionales sanitarios y científicos podemos aspirar a publicar el resultado de nuestra labor asistencial. 